\title{
Stanley Smith at the Moor Hospital
}

\author{
Mary Ann Watts-Tobin, FRCPsych
}

Dr Smith brought his family to Lancaster and took up his post of medical superintendent in 1957. The hospital had nearly 3,000 patients and overcrowded wards in old buildings. Twenty percent of the population was elderly and there were only three trained psychiatrists.

There were similar conditions in many asylums when they were taken into the NHS. The Mental Health Standing Advisory Committee, appointed to advise the government, at first recommended building new hospitals as numbers of patients continued to grow till the mid 1950s. They noted the shortage of medical staff and difficulty in recruiting junior doctors to work in asylums, which were often geographically isolated and far from training facilities. They recommended the establishment of academic departments of psychiatry in teaching hospitals.

Eventually, alternatives to treatment in hospital became the favoured solution and the Hospital Plan of 1962 envisaged the complete rundown of the asylums and community treatment in day hospitals and outpatient departments, with accommodation in hostels and boarding-out schemes.

Dr Smith came with strong credentials as a physician (MD $\mathrm{MRCP}$ ) and in academic psychiatry. He had experience of a small hospital specialising in admissions and short-term care and its relationship with the large mental hospital in the same city (Bristol). At the same time, the Manchester Region was well in advance of national trends in that enterprising psychiatrists had set up psychiatric admission units in general hospitals, first at Oldham and later at Burnley, Bolton and Blackburn. He saw such units as the way forward that would allow the eventual rundown of the big hospitals.

In the articles that he published in The Lancet between 1959 and 1969 we can follow the changes he steered through at the Moor. ${ }^{(1.23)}$

He opened the wards, leaving only two, for disturbed and detained patients, locked. As the hospital numbers started to reduce (partly due to the effectiveness of chlorpromazine in the treatment of psychosis from 1953) he believed that empty wards could be re-used to meet local medical and surgical needs and take advantage of existing onsite facilities such as pathology, pharmacy, radiology, physiotherapy and EEG. He adopted the idea of the Comprehensive Hospital described by McKeown, ${ }^{(4)}$ in which acute and chronic patients were cared for under one roof. The Garnet Clinic, housed in the south end of the huge annexe building at the Moor, eventually provided wards for medicine, surgery, neurosurgery, orthopaedics and ophthalmology, and had surgical theatres.

Concerning staff of the hospital, he used money for nonexistent junior doctors to fund general practitioner (GP) sessional work, mainly to cover physical care but also some psychiatric care. The GPs provided practical, up-to-date care and good continuity: the nurses and patients were very enthusiastic about this arrangement and it allowed the psychiatrists to concentrate on their speciality.
He put the foundations in place for a geriatric service by sorting out the elderly patients into those with continuing psychiatric problems and those with purely organic and agerelated conditions. These last (300 males and 500 females!) were assembled in special wards and the first consultant geriatrician was in post by the mid 1960s.

He developed Ridge Lea (previously long-stay female wards) as the admission and short-term unit for psychiatry, serving Lancaster, Morecambe, Kendal, Ulverston, Barrow, Blackpool and Fylde.

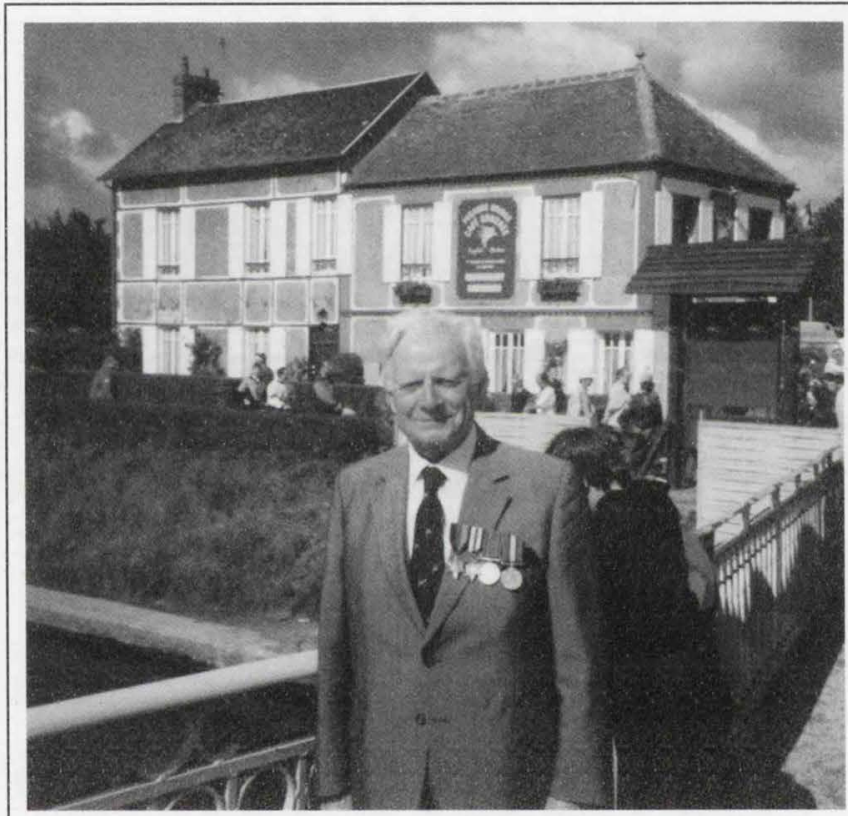

Stanley Smith at Pegasus Bridge, Normandy. He was part of the Airborne Division, which took this bridge over the Caen Canal during the D-Day landings (June 1944)

His 1969 paper records further developments: $:^{(3)}$

- a 12-bed child psychiatry unit with two consultants and educational staff

- an inpatient alcohol treatment unit

- a school of radiography

- a geriatric day hospital

- a sub-regional blood transfusion unit with consultant haematologist

Dr Smith did not agree with The Lancet when it described the asylums in 1968 as 'antique monstrosities' and 'mausolea for living', feeling that the Moor and others were adapting themselves, continuing to provide back-up to small admission units by taking persistently disturbed patients, and continuing to reduce in size and develop community psychiatry. He also observed the tragic consequences of discharging long-stay patients into the community without proper facilities, continuing support and occupation. 
I have not mentioned his important regional and national committee work, nor his time at Whittingham Hospital. I have concentrated on his work at the Moor as he saw it, relying on his publications and on his conversation with Professor Hugh Freeman. ${ }^{(5)}$ Dr Smith died, aged 91, in January 2010 and his obituary was published in The Psychiatrist. ${ }^{(6)}$

At the time of his appointment, there had been much controversy about the post of superintendent, now the asylums were under the NHS and had consultants. He decided to be superintendent as he felt that he would have close contact with the Hospital Management Committee and Hospital Secretary and be able to influence them and bring desirable changes to fruition. He said that they would not be able to ignore him(!) and they did not.

\section{REFERENCES}

I. Smith S, Gibb GM, Martin AA. Metamorphosis of a mental hospital. Application of McKeown's comprehensive unit. Lancet 1960;2(7I50):592-3

2. Smith S, Gibb GM, Martin AA. Using mental hospitals for other purposes. Lancet 1963:2(7304):398-400

3. Smith S, Gibb GM. Dissolution of a mental hospital. Lancet 1969:2(7626):893-5

4. McKeown,T.The concept of a balanced hospital community Lancet 1958; | (7023):70 I-4

5. Freeman HL. In conversation with Stanley Smith. Psychiatr Bull R Coll Psychiatr 1991; 15(9):529-53

6. Smith C. Obituary: Dr Stanley Smith. Psychiatrist $2010 ; 34(10): 455$

\section{QUID EST HOC?}

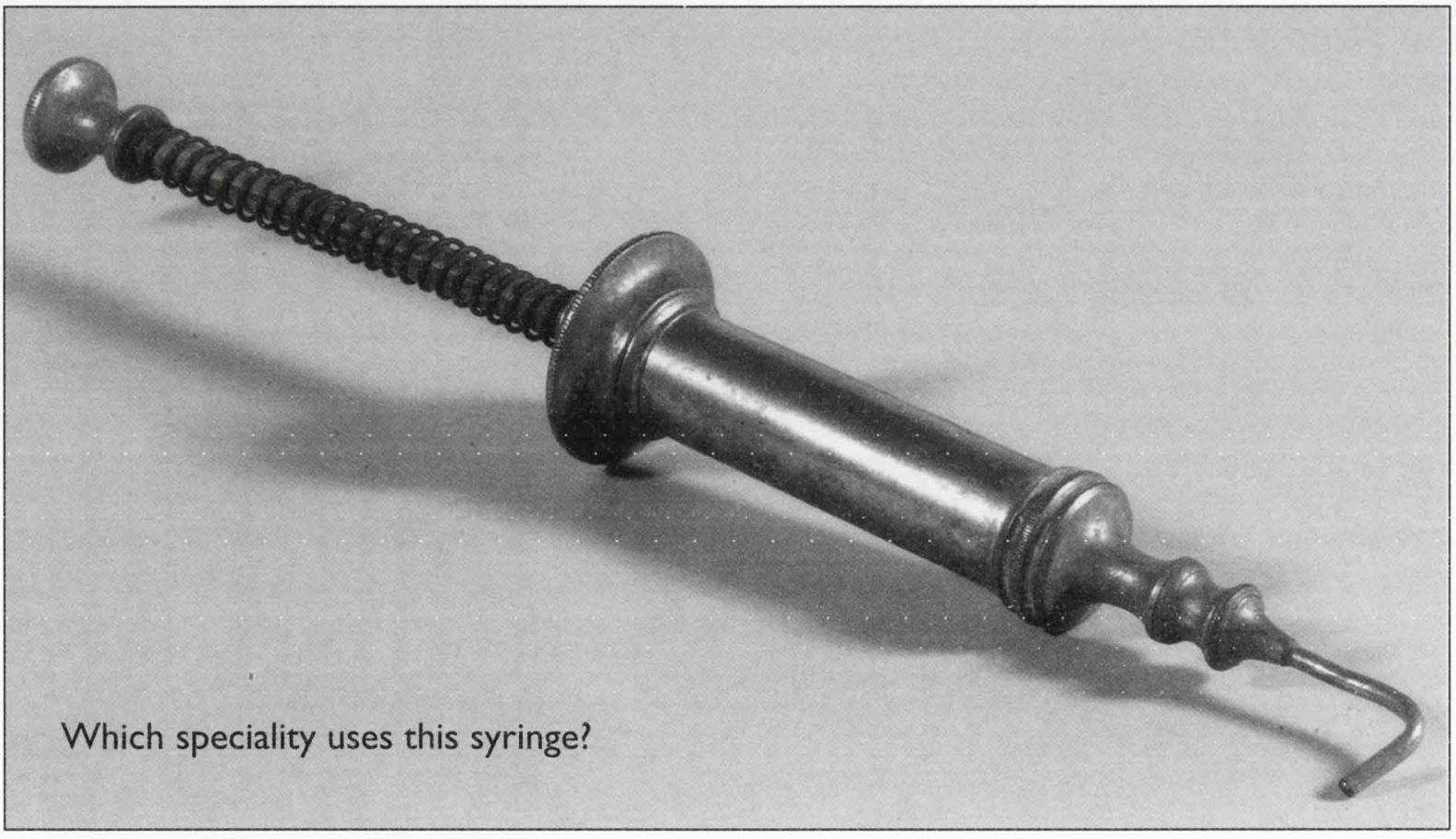

Please send answers to the Editor, Morecambe Bay Medical Journal, Education Centre, RLI, LAI 4RP.
A $£ 25$ book token will be awarded for the first correct answer to be drawn at random. 